\title{
Comparative Study of Air Conditioning Systems
}

\author{
Harouna Mamadou BAL, Vincent SAMBOU, Mactar FAYE, Youssouf MANDIANG
}

\begin{abstract}
This work consists in comparing systems of air-conditioning with mechanical compression equipping buildings according to their yearly energy consumptions and maintenance costs. Our study showed that it does exist an important difference while leaving from one system to another. The variable air or flow system is most interesting in terms of energy consumption, then comes the child water system and finally respectively fixed airflow rate central airconditioning and the PTAC air-conditioning in whole our study field.
\end{abstract}

Key Words: Air-conditioning system, comparison of performances, energy consumption and simulation of thermal loads.

\section{NOMENCLATURE}

\begin{tabular}{|c|c|}
\hline Greek Letters: & tb Light butlb \\
\hline P Density, $\mathrm{kg}_{\mathrm{g}} \mathrm{m}^{3}$ & Symbols : \\
\hline$\tau$ Air exchange rate per person, $\mathrm{m}^{3 / \mathrm{s}}$ & IAC Individual Air Conditionner \\
\hline Indices / Exponents : & CWS Chilled Water System \\
\hline gw Glazing and windows & VRF Variable Refrigerant Flow \\
\hline d Door & Q Heat flow in W \\
\hline ew Exterior wall. & GLF Glazing factor of glazing in W/m ${ }^{2}$ \\
\hline ef Exposed floor & ETD Equivalent temperature difference, $\mathrm{K}$ \\
\hline pz Partition zone & $\mathrm{U}$ Overall tranfer coefficient, $\mathrm{W} / \mathrm{m}^{2} \mathrm{~K}$ \\
\hline IC Roof and celing. & A Surface of element, $\mathrm{m}^{2}$ \\
\hline ea External air & $\Delta \mathrm{T}$ Temperature difference, $\mathrm{K}$ \\
\hline ia Internal air & H Mass enthalpy, J/kg \\
\hline b Bulb & $\mathrm{N}$ Number of \\
\hline
\end{tabular}

\section{INTRODUCTION}

Since the first " oil shock " of the 1970s, great progress has been made in the development of energy policies taking into account this new fact that has been the most expensive energy. Considerable progress has also been made in applying

Harouna Mamadou BAL, ${ }^{1}$ Laboratoire des Matériaux et d'Energétique de l'IUT, Université de Thies Sénégal, ${ }^{2}$ Laboratoire d'Energétique Appliquée de l'ESP, Université Cheikh Anta DIOP de Dakar Sénégal

Vincent SAMBOU, ${ }^{2}$ Laboratoire d'Energétique Appliquée de l'ESP, Université Cheikh Anta DIOP de Dakar Sénégal

Mactar FAYE, '2Laboratoire d'Energétique Appliquée de l'ESP, Université Cheikh Anta DIOP de Dakar Sénégal

Youssouf MANDIANG, ${ }^{2}$ Laboratoire d'Energétique Appliquée de l'ESP, Université Cheikh Anta DIOP de Dakar Sénégal these policies and in controlling energy in the various sectors of human activity [1]. It is in the frame of support to this policy of control of the energy that we were interested in this aspect of this work and initiated the publication of this article for the extension.

\section{METHODOLOGY}

As a support, we used a software package E20-II which is a trademark of Carrier Corporation; it normally uses ASHRAE methodologies. Among this series of software, we have essentially used that of the hourly analysis called HAP. It brings together two programs in one. One is used to calculate the thermal loads of buildings to facilitate the study of the air conditioning system. The other calculates the annual energy requirements and the costs of functioning; this allows for comparisons between various air conditioning systems. Energy analysis is a method of simulating building and system loads over a period of one year to assess energy consumption and operating costs. By simulating performance on each of the 8,760 hours of a year, HAP can provide the most accurate assessments of energy consumption and operating costs. In fact, the HAP simulations use real time climate data and take into account the real dynamic behavior of the building and its equipment from hour to hour and from day to day. These are factors that must be taken into account when comparing performance differences between different systems, control modes and equipment types.

\section{DATA}

Geographic and climatic conditions

- City: Dakar,

- Country: Senegal

- Latitude: $14^{\circ} 42$ North,

- Altitude: $0 \mathrm{~m}$

- Base dry temperature " summer ": $35^{\circ} \mathrm{C}$

- Base relative humidity " summer ": $75 \%$

- Diurnal difference: $6{ }^{\circ} \mathrm{C}$

Maximum sunshine

Maximum sunlight in W.m-2 (maximum solar flux from January to December) at Dakar, at $14^{\circ} 28$ latitude North), obtained by interpolation of the 


\section{Comparative Study of Air Conditioning Systems}

maximum values between the latitudes 10 and $20^{\circ}$ North is given by the tables below :

\begin{tabular}{|c|c|c|c|}
\hline Orientation & North & N-E/N-W & E-W \\
\hline Jan/Nov & 24 & 90 & 377 \\
\hline Feb/Oct & 27 & 166 & 418 \\
\hline Mar/Sep & 28 & 265 & 449 \\
\hline Apr/Aug & 34 & 346 & 450 \\
\hline May - Jul & 71 & 397 & 440 \\
\hline June & 95 & 422 & 434 \\
\hline Dec & 24 & 66 & 358 \\
\hline Orientation & S-E/S-W & South & Horizontal \\
\hline Jan/Nov & 447 & 330 & 544 \\
\hline Feb/Oct & 421 & 242 & 607 \\
\hline Mar/Sep & 364 & 118 & 664 \\
\hline Apr/Aug & 280 & 52 & 685 \\
\hline May - Jul & 202 & 39 & 683 \\
\hline June & 171 & 39 & 664 \\
\hline Dec & 453 & 362 & 520 \\
\hline
\end{tabular}

Tableau 1: Summary of maximum sunshine data in Dakar, Sénégal

Average temperatures in January and August

Seizure data including climatic conditions; the operation of the system is simulated hour by hour, for the average load conditions and climatic conditions indicated [2] in the table below:

\begin{tabular}{|c|c|c|c|c|c|}
\hline Time & January & August & Time & January & August \\
\hline 1 & 21,3 & 26,4 & 13 & 25,4 & 28,7 \\
\hline 2 & 21,1 & 26,7 & 14 & 25,9 & 29,1 \\
\hline 3 & 21 & 26,6 & 15 & 26 & 29,1 \\
\hline 4 & 20,8 & 26,4 & 16 & 26 & 29,4 \\
\hline 5 & 20,9 & 26,2 & 17 & 25,6 & 29,3 \\
\hline 6 & 20,7 & 26,2 & 18 & 25 & 29 \\
\hline 7 & 20,6 & 26,1 & 19 & 24 & 28,5 \\
\hline 8 & 20,4 & 20 & 20 & 22,8 & 27,9 \\
\hline 9 & 20,2 & 26,2 & 21 & 22,1 & 27,4 \\
\hline 10 & 21,1 & 26,6 & 22 & 21,8 & 27,2 \\
\hline 11 & 23 & 27,5 & 23 & 21,7 & 27 \\
\hline 12 & 24,5 & 28,2 & 24 & 21,5 & 26,8 \\
\hline
\end{tabular}

Tableau 2: Averages temperatures in January and August in Dakar, Sénégal

IV. MATHEMATICAL MODEL
The building studied is an eight-storey building located in Dakar. The choice of this office building seems relevant to us in that it has already been the subject of a case study as part of the research to implement the energy efficiency of the UNDP / ENERBAT project, study conducted in part by the Applied Energetics Laboratory LEA. In fact; many of its physical parameters are therefore available in the literature. Moreover, from the study of the UNDP / FEL / RAF / G32 Regional Project, it appears that the share of air conditioning represents a very important part of the total energy consumption of the building.

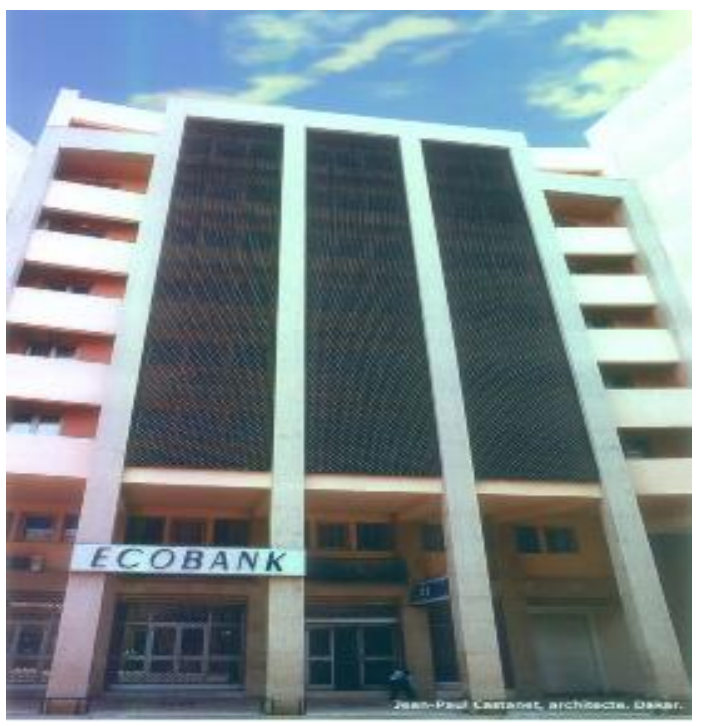

Figure 1: Photograph of studied building

A heat balance calculation procedure derived from [3] and similar to that developed in [4], [5], [6], [7], [8] and [9] was applied to the building model through [10] and is summarized as follows:

Heat flow through glazing and windows is given by:

$$
Q_{1}=(G L F) \cdot A_{g w}
$$

Heat flow through the doors is given by:

$$
Q_{2}=(E T D) \cdot U_{d} A_{d}
$$

Heat flow through exterior walls is given by:

$$
Q_{3}=(E T D) \cdot U_{e w} \cdot A_{e w}
$$

Heat flow through the partition zones (adjacent walls) is given by:

$$
Q_{4}=\Delta T \cdot U_{p z} \cdot A_{p z}
$$

Heat flow input through roofs and ceilings is given by:

$$
Q_{5}=(E T D) \cdot U_{r c} \cdot A_{r c}
$$

Heat flow input through the exposed floors is given by the expression: 


\section{Comparative Study of Air Conditioning Systems}

$$
Q_{6}=(E T D) * U_{e f} \cdot A_{e f}
$$

Heat flow input through the infiltrations is given by:

$$
Q_{7}=\tau_{r a} \cdot \rho \cdot\left(H_{e i}-H_{i a}\right)
$$

The rate per person for sensible heat contribution is given by:

$$
Q_{8}=67 \mathrm{~W}
$$

The rate per person for latent heat contribution is given by:

$$
Q_{9}=37 W
$$

The heat flow relative to lighting is given by:

$$
Q_{10}=N_{b} P_{l b}
$$

\section{SIMULATION AND RESULTS}

Simulation

The HAP containing algorithms within it, is capable of simulating the performance of equipment intended to control the thermo-hygrometric conditions of each zone within the building. With this, it uses information resulting from the load calculation program and the characteristics of each system to calculate hour by hour the energy required by the system according to the variations of each parameter of the area. The input data for the simulation includes climatic conditions, space information, and criteria introduced in the HAP branch, dealing with the climatic conditions of the space, as well as the air conditioning system data introduced., using the data menu of the air conditioning system. The operation of the system is simulated hour by hour for average load conditions and climatic conditions.

Results

The HAP containing algorithms within it, is capable of simulating the performance of equipment intended to control the thermo-hygrometric conditions of each zone within the building. With this, it uses information

\section{Thermal balance}

The application of the software on the chosen building model gave the maximum cooling balance of each building in August at $3 \mathrm{pm}$ :

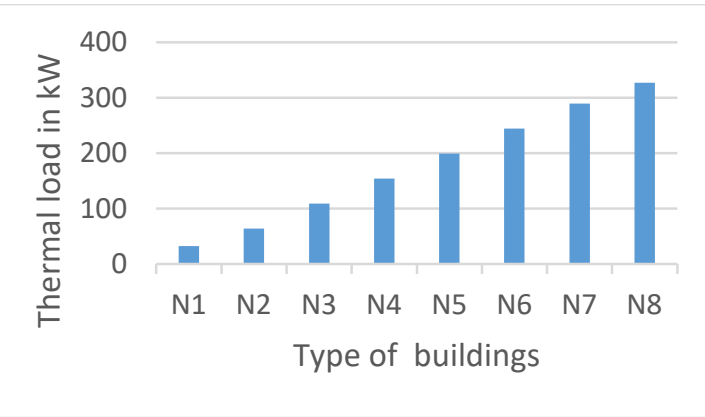

Figure 2: Thermal load profile of different buildings

\subsubsection{Comparison of installed refrigerating capacities}

To make a fairly strict comparative study, from the selection of equipment for model buildings, we studied the refrigeration capacities installed for each system according to the load.

The fact that all the curves are confounded regardless of the size of the building and the equipment chosen, shows that no system induces an excess of installed power compared to another.

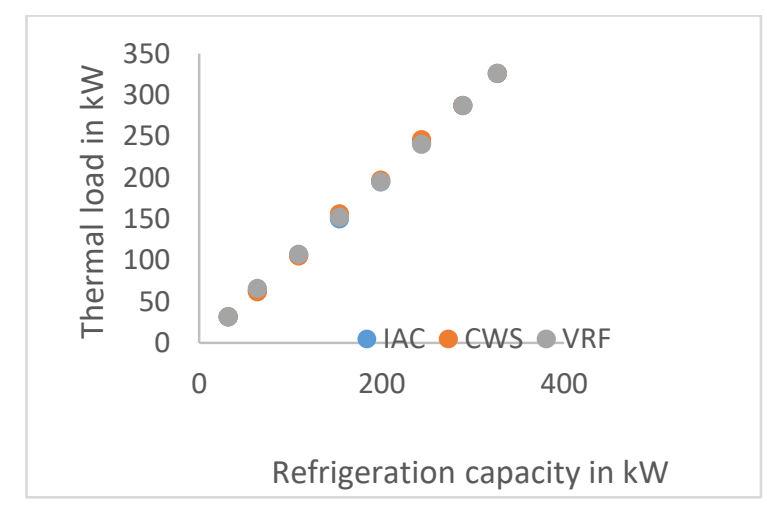

Figure 3: The Installed refrigeration capacity of each system according to the load in $\mathrm{kW}$

\subsubsection{Energy consumption per year}

The principle is based on the operation of the systems of 8 hours a day and 5 days a week. A simulation of the three systems over this sequential period gives the profile of the annual consumption of each system. After the thermal balance calculation carried out initially, the annual energy consumption is determined, the results of which are given below:

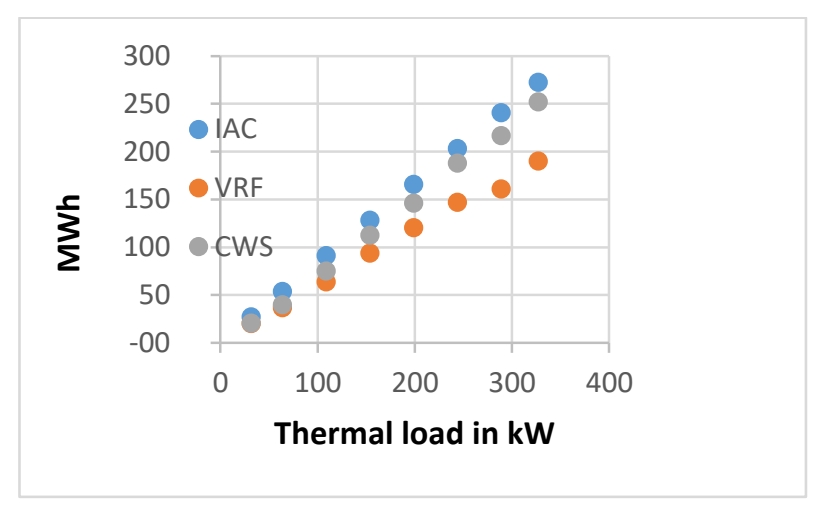

Figure 4: Annual energy consumption profile

In view of the results and in relation to the essential criterion of energy consumption, it is clear from our study that the VRF system is the most interesting then the chilled water system comes in second position with a more interesting behavior when increasing the load and finally the individual air conditioning that is more energetic over the whole range of our study. 


\section{Comparative Study of Air Conditioning Systems}

\subsubsection{Acquisition cost of equipment}

A no less important criterion to take into account is the acquisition cost of the equipment. It can be obtained after having determined the maximum cooling capacity per space, therefore the configuration of the installation according to the chosen system. This makes it possible to proceed to a count of elements to be installed and to make a quotation.

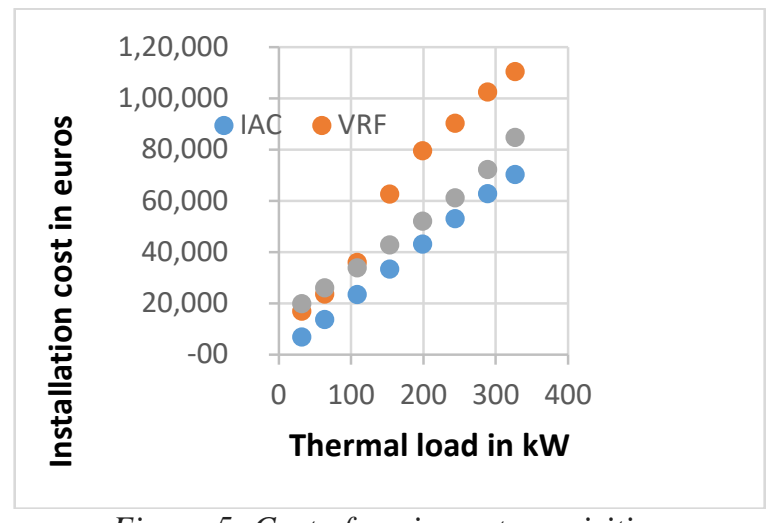

Figure 5: Cost of equipment acquisition

In view of the results, we note that the individual climate is more accessible over the entire range of thermal load.

Low power up to around $110 \mathrm{~kW}$, the VRF system is more accessible but the trend is reversed compared to the chilled water system.

\section{CONCLUSION}

For a global comparison of systems, other factors must be integrated. Thus, looking at the criterion as the cost of acquisition we note a reversal of curves; this is why it is interesting in the context of the ongoing work to increase the comparison criteria among others (consumption, operating cost, acquisition cost, ease of execution, availability of equipment, service life of environmental impact installations for the questioning of certain fluids dangerous for the greenhouse effect), to explore new calculation tools that take into account the new machine designs and to make an economic calculation on the returns of investment to find an optimum.

\section{REFERENCES}

[1] Guide de 1'Energie. Stratégie, Energie, Environnement et Développement. Ministère de la Coopération et du Développement de la République Française, 1998.

[2] https:// climate-data.org $>$ Afrique $>$ Sénégal

[3] ASHRAE Fundamentals (SI), 1997

[4] Libert A., Le calcul de charges calorifiques en conditionnement d'air, éditions Chaud-Froid-Plomberie, CFP, 1976.

[5] ConsoClim : Méthode informatisée de calcul de consommation des bâtiments climatisés destinée à l'optimisation bâtiment + équipements en phase d'esquisse ou d'avant-projet, développée par AICVF et CSTB.

[6] E20-II, Carrier Software systems - Version 1.12

[7] BOHLER A. et al., Méthodes de calcul des consommations d'énergie dans les bâtiments climatisés par CONSOCLIM, rapport CSTB ENEA/CVA-99 176R, janvier 2000

[8] Paul Lang P., Principles of air conditioning, Cengage Learning, Third Edition, 1995

[9] Manohar Prasad., Refrigeration and air conditioning. New Age International (P) limited, publishers, 1998.
[10] DOE2 Logiciel d'analyse de performance de bâtiments développée par le groupe de recherche du laboratoire national de Lawrence BERKLEY in USA, 1999.

${ }^{*}$ Corresponding author.

E-mail address: harouna.bal@univ-thies.sn (Harouna Mamadou $\mathrm{BAL})$ 